\title{
THE UNHAPPY TRIAD: BLOOD, SWEAT AND SORROW
}

\author{
(It is always easy to be wise after the event. Arthur Conan Doyle)
}

"There are three methods to gain wisdom; the first is reflection which is the highest. The second is imitation which is the easiest. The third is experience which is the bitterest. Confucius 551-479 BC"

\section{Thamer A Hamdan ${ }^{\circledR}$}

${ }^{\circledR} \mathrm{MB}, \mathrm{ChB}$, FRCS, FICS, FACS, FRCP, American Board of Neurological \& Orthopaedic Surgery, Professor of Orthopedic Surgery, Research Fellow in Saint George's University Hospital, London, Visiting Professor, Imperial College, London, UK.

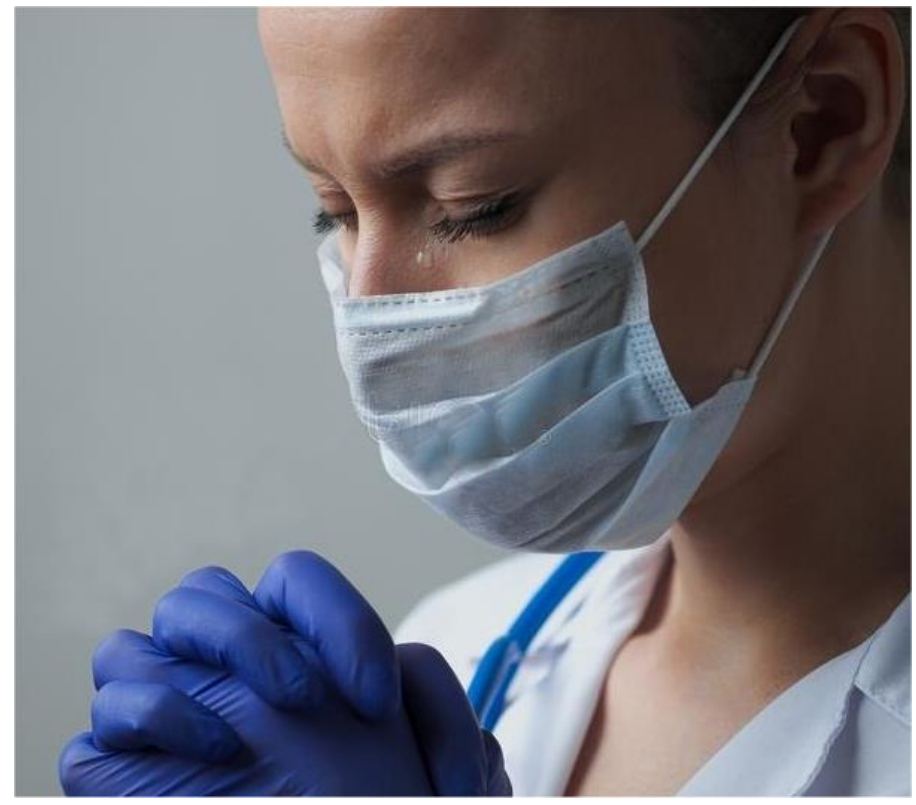

Qir Winston Churchill in his famous saying in 1940; I have nothing to offer but blood, toil, tears, and sweat. He warned the British people of the suffering in World War II, now I am using his words to warn surgeons about this unhappy triad. This triad came from biblical source and surprisingly a jazz-rock band in 1967 started to use this triad as a name for their jazz. Also many books in Amazon carry more or less similar words.

Starting with bleeding which is a real panic at time of operation, particularly when it is profuse and unexpected. Some may have disorientation and lack of control. Patients may die on the table or need intensive resuscitative measures. This is a situation all surgeons hate to face including myself. It is usually avoidable condition if the standard safety measures are considered seriously particularly for patients who are at risk such as those on anticoagulants, aspirin or other drugs. Some anaesthetic medications such as halothane produce vasodilatation which increase bleeding. Patients with hematological disorders and certain pathology like malignant or infective lesions may bleed profusely at the time of surgery so they need a very special preoperative preparation and particular precaution in the intraoperative time. Operating on secondaries from thyroid carcinoma or renal cell cancer may lead to plentiful bleeding and on table death. 
Anatomical variation with aberrant vessels may create a trouble during operation. Poor surgical technique, improper dissection, forgetting the normal anatomy, and certain types of operations all may carry definitive risk of vascular injury in hands of a surgeon who have lack of wisdom and is in rush. In his endeavor to spare time he may lose all the time. Positioning of the patient on the operating table may lead to venous congestion like in prone position so unexpected bleeding may be faced. Patients with bad habits like smoking and alcohol consumption may have excessive oozing.

The key for success in controlling intraoperative bleeding is the surgeon's ability to control unexpected storm and to master the proper technique even in a very delicate sites.

Sudden rise in blood pressure may change the field to a pool of blood. On the contrary, hypotension is good and bad, good in reducing bleeding like deliberate hypotension, bad because it hides some bleeders which can not be detected at time of surgery but later causes postoperative bleeding.

The surgeon should always remember the hidden and forgotten causes of intraoperative bleeding such as; hypothermia, acidosis, hemodilution, and prolonged surgery in addition to being capable of defeating the expected and unaccepted surgical storm as soon as the situation dictates.

Our aim is to optimize operative procedure, reduce postoperative complications, and improve recovery. If we achieve this goal, we can protect our dear patients far away from the sweat, tears, sorrow, and disappointment. Emergency blood transfusion may carry many risks and even morbidity and mortality. Having a prepared blood is like having a spare tire in your car when you drive in the dessert.

Sadly some surgeons collapse before the patient's collapse when the surgical field becomes a lake of blood, in this situation it is safer to ask the help of a free colleque to rescue this dangerous circumstance before the surgeon start shedding sweat in the operative field. Sweating can occur in some parts of the body after receiving a green light from the nervous system. Excessive sweat secretion is the outcome of stressful condition, sweat can actually tell about the degree of tension. Personally, I feel nothing more stressful than having a surgical hemorrhage storm, so the surgeon after facing a plentiful bleeding in the field, he will pour sweat hopefully not inside the wound. In mind, there is individual variation in sweat production after anxiety. The stress sweat contains fat, protein, and bacteria while sweat in normal state is salty water. After all, the drop of blood is heavier and more precious than a drop of sweat or tear.

Sorrow is the outcome of bad result of surgery. Sorrow is a feeling of deep distress and disappointment caused by defeat. It may last for long time or make the surgeon hate his career because of guilt feeling and blaming himself for the high morbidity or even mortality of his patients. On the other hand, sorrow might be a good lesson for the surgeon to improve his surgical skills and approaches. Unfortunately, the surgeons are not always feeling blameworthy after the bad happening of the surgical practice.

Finally, the question arises; is it possible to avoid facing the sad triad? The answer will come with yes always and that is by: Proper preoperative preparation with extra precaution, full understanding of the normal and abnormal anatomy keeping in mind the variations, empathy drive the surgeon to be wise and insightful in his clinical reasoning and decision making, critical balance between the benefit and harm may prevent shedding sweat and tears, having the wisdom not only to treat but to heal which is mandatory in surgical practice, mastering surgical techniques and asking help of a colleque is a good protective measure against pouring sweat $\&$ tears and suffering grief . 